\title{
MAGNITUDE OF CARDIAC INVOLVEMENT IN DENGUE FEVER
}

\author{
Banwari Lal Yadav ${ }^{1}$, Leeneshwar Harshvardhan², Kuldeep Singh Yadav ${ }^{3}$
}

${ }^{1}$ Medical Officer, SDH, Kotputli.

2Professor, Department of Medicine, SMS Medical College and Attached Hospital, Jaipur.

${ }^{3}$ Senior Resident, Department of Psychiatry, SMS Medical College and Attached Hospital, Jaipur.

\section{ABSTRACT}

\section{BACKGROUND}

The present study was conducted to find out the proportion of dengue fever cases with cardiac involvement.

\section{MATERIALS AND METHODS}

It was a hospital based observational descriptive study. 104 eligible dengue fever cases were selected for the study. Appropriate investigations were done.

\section{RESULTS}

It was found that a significant number of patients of dengue developed asymptomatic involvement of heart as evidenced by electrocardiography changes, raised cardiac enzymes.

\section{CONCLUSION}

Myocardial involvement in most of the cases was found to be subclinical on 2-D echo.

\section{KEYWORDS}

Dengue, Myocardial Involvement.

HOW TO CITE THIS ARTICLE: Yadav BL, Harshvardhan L, Yadav KS. Magnitude of cardiac involvement in dengue fever. J. Evolution Med. Dent. Sci. 2017;6(7):570-574, DOI: 10.14260/Jemds/2017/122

\section{BACKGROUND}

Dengue fever (DF), the most prevalent arthropod-borne viral illness in humans, is caused by the dengue virus (DENV). The 4 serotypes of DENV (DENV 1-4) are transmitted to humans primarily by the Aedes aegypti mosquito.[1] Dengue is the most rapidly spreading mosquito-borne viral disease in the world. In the last 50 years, incidence has increased 30 -fold with increasing geographic expansion to new countries and in the present decade from urban to rural settings. An estimated 50 million dengue infections occur annually and approximately 2.5 billion people live in dengue endemic countries.[2]

Severe dengue infections may give rise to many complications such as liver failure, disseminated intravascular coagulation, encephalopathy, myocarditis, acute renal failure, and haemolytic uremic syndrome. [3] Although these complications are generally rare, in recent years they have been reported with increasing frequency. Although shock in DHF/DSS has been attributed largely to decreased intravascular volume due to capillary leakage of plasma into the interstitial space, a few recent studies have reported that it may be due to cardiac involvement. $[4,5,6,7]$

Some authors reported direct cardiac involvement in dengue fever patients (Obeyesekere[8] and Hermon, 1973; Wali et al 1998[5]; Promphan et al 2004[9]). Their study investigated the extent of myocardial involvement in dengue

Financial or Other, Competing Interest: None.

Submission 10-12-2016, Peer Review 10-01-2017,

Acceptance 16-01-2017, Published 23-01-2017.

Corresponding Author:

Dr. Banwari Lal Yadav,

C/o. Doormal Yadav,

$B-3$, Sharma Colony,

Kartarpura Phatak, Jaipur-302015.

E-mail: drbanwari2003@gmail.com

DOI: $10.14260 /$ jemds $/ 2017 / 122$

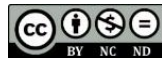

fever patients, compared with other groups with infectious diseases. (Ehrhardt et al, 2004, 2005).[10]

The purpose of this study was to assess whether there is any form of cardiac involvement (Clinical or subclinical) in dengue and DHF, because most of our dengue patients had raised cardiac markers.

\section{Aims \& Objectives \\ To find out the proportion of Dengue Fever cases with cardiac involvement.}

\section{MATERIALS \& METHODS}

This study was conducted in the Department of General Medicine, S.M.S. Medical College \& Attached Group of Hospitals, Jaipur. It was a hospital based observational descriptive study and was carried out from April 2014 to August 2015.

104 eligible dengue fever cases were included on first come first basis after beginning of the study.

The local research ethics committee approved the study. All patients gave written informed consent to participate; for those patients in critical condition or aged $<18$ years, an informed consent was obtained from their relatives or legal guardians.

Both primary dengue (NS-1 antigen or IgM or both positive) and secondary (NS-1 antigen or IgM and IgG antibody positive) dengue cases were included. Patients who had any known cardiac disease, chronic kidney disease, diabetes mellitus, hypertension were excluded. Blood samples of probable dengue patients were tested for NS1 antigen using ELISA technique from the kit supplied by Pan Bio-company. Dengue IgM antibody MAC ELISA kit supplied by SD Company. IgG ELISA by rapid test kit supplied by SD company.

The following parameters were considered and/or measured in all patients: Age, gender, blood pressure, routine 
blood inv., NS-1 antigen, IgM and IgG antibody, CK-MB, ECG, Trop-T, 2-D echo. Inferences were drawn with use of appropriate test of significance. The categorical data were presented as numbers (percent) and were compared among groups using Chi square test. Groups were compared for demographic data, were presented as mean and standard deviation and were compared using by students t-test. Probability $P$ value $<0.05$ was considered statistically significant.

\section{RESULTS}

\begin{tabular}{|c|c|c|}
\hline ECG Changes & $\begin{array}{c}\text { No. of } \\
\text { Patients }\end{array}$ & Percentage \\
\hline WNL & 76 & 73.08 \\
\hline Involved & 28 & 26.92 \\
\hline $\begin{array}{c}\text { Generalised T wave } \\
\text { inversion }\end{array}$ & 3 & 10.71 \\
\hline Sinus bradycardia & 9 & 32.14 \\
\hline Sinus tachycardia & 7 & 25.00 \\
\hline ST depression in V1-V6 & 3 & 10.71 \\
\hline ST depression in V1-V4 & 3 & 10.71 \\
\hline T inversion in V2-V5 & 2 & 7.14 \\
\hline T wave inversion in V1-V4 & 4 & 14.29 \\
\hline Generalised ST elevation & 1 & 3.57 \\
\hline Low voltage & 3 & 10.71 \\
\hline ST-T changes in V2-V5 & 2 & 7.14 \\
\hline ST-T changes in V3-V6 & 2 & 7.14 \\
\hline T wave inv. Lead 2, 3 & 1 & 3.57 \\
\hline \multicolumn{3}{|c|}{ Table 1. ECG Changes } \\
\hline
\end{tabular}

$\mathrm{N}=104$

\begin{tabular}{|c|c|c|c|c|}
\hline CK-MB(U/L) & $\begin{array}{c}\text { No. of } \\
\text { Patients }\end{array}$ & Mean & $\begin{array}{c}\text { Std. } \\
\text { Deviation }\end{array}$ & P Value LS \\
\hline Normal & 65 & 22.01 & 0.31 & \multirow{2}{*}{$<0.0001 \mathrm{~S}$} \\
\hline Elevated & 39 & 93.64 & 5.82 & \\
\hline \multicolumn{5}{|r|}{ Table 2. Dengue Cases According to CK-MB with Cardiac } \\
Involvement \\
\hline
\end{tabular}

\begin{tabular}{|c|c|c|}
\hline Troponin T test & No. of Cases & Percentage \\
\hline Positive & 9 & 8.65 \\
\hline Negative & 95 & 91.35 \\
\hline Total & 104 & 100 \\
\hline
\end{tabular}

\begin{tabular}{|c|c|c|}
\hline Echo Finding & $\begin{array}{c}\text { No. of } \\
\text { Patients }\end{array}$ & $\begin{array}{c}\text { Percen- } \\
\text { tage }\end{array}$ \\
\hline Global hypokinesia, LVEF-50\% & 1 & 3.57 \\
\hline Grade 1 diastolic dysfunction & 1 & 3.57 \\
\hline LV systolic dysfunction, EF-49\% & 1 & 3.57 \\
\hline Mild MR, trivial TR & 1 & 3.57 \\
\hline Mild pericardial effusion & 5 & 17.86 \\
\hline Severe LV dysfunction & 1 & 3.57 \\
\hline RA, RV dilated, RV hypokinesia & 1 & 3.57 \\
\hline Grade 1 LVDD, EF-53\% & 1 & 3.57 \\
\hline Lt. ventricular hypokinesia & 1 & 3.57 \\
\hline LVEF-45\% & 1 & 3.57 \\
\hline Severe TR, mild MR, LVEF-46\% & \multicolumn{2}{|c|}{} \\
\hline \multicolumn{2}{|c|}{ Table 4. Echo Finding with Cardiac Involvement } \\
\hline
\end{tabular}

All Dengue cases $(\mathrm{N}=104)$

\begin{tabular}{|c|c|c|}
\hline Finding & No. of Cases & Percentage \\
\hline Abnormal CK-MB(U/L) & 39 & 37.5 \\
\hline Abnormal ECG & 28 & 26.92 \\
\hline Abnormal Echo findings & 9 & 8.65 \\
\hline Abnormal Troponin T & 9 & 8.65 \\
\hline \multicolumn{2}{|c|}{ Table 5. Assessment of Cardiac Involvement via } \\
Various Investigation Modalities \\
\hline
\end{tabular}

\begin{tabular}{|c|c|c|}
\hline Cardiac Involvement & No. of Cases & Percentage \\
\hline Present & 28 & 26.92 \\
\hline Absent & 76 & 73.08 \\
\hline Total & $\mathbf{1 0 4}$ & $\mathbf{1 0 0}$ \\
\hline \multicolumn{2}{|r|}{ Table 6. Distribution of Dengue Cases } \\
According to Cardiac Involvement \\
\hline
\end{tabular}

In our sample, maximum patients were within 21 to 30 years of age group. Out of 104 patients, most were male.

Out of 104 dengue patients, abnormal ECG findings were in 28 patients, most common ECG finding was sinus bradycardia in 9 patients $(32.14 \%)$, next was sinus tachycardia in 7 patients (25\%) and T-wave inversion in V1V4 and V2-V5 was in 4 and 2 patients respectively. ST depression in V1-V4 and V1-V6 was in 3 patients each, generalised $\mathrm{T}$ inversion and low voltage in 3 patients each, ST-T changes in V2-V5 and V3-V6 both were in 2 patients each, generalised ST elevation and T wave inversion in lead 2 , 3 were in 1 patient each. (Table 1 ).

Among these 28 patients, abnormal echo finding was present in 9 patients $(32.14 \%)$. The most common finding was mild pericardial effusion in 5 patients $(17.86 \%)$. (Table 4).

Among these 104 patients, the mean Value of CK-MB $(\mathrm{U} / \mathrm{L})$ was significantly higher in the cases with cardiac involvement as compared to normal which was statistically significant $(\mathrm{P}<0.0001 \mathrm{~S})$ (Table 2$)$.

Out of 104 patients, 9 patients $(8.65 \%)$ were troponin $\mathrm{T}$ positive and 95 (91.35\%) were troponin T Negative (Table 3). Out of 104 patients, 39 patients (37.5\%) had elevated CK-MB and 28 patients $(29.92 \%)$ had abnormal ECG findings, and abnormal 2-D echo and abnormal Troponin $\mathrm{T}$ seen in 9 patients (8.65\%) in each. (Table 5).

Out of 104 patients, 28 patients $(26.92 \%)$ had cardiac involvement and 76 patients (73.08) did not have cardiac involvement. (Table 6).

\section{DISCUSSION}

Dengue fever is known to affect several systems in the human body. As in any viral myocarditis, only a portion of the patients (8.65\%) had 2-D echocardiographic evidence of myocarditis. Myocardial involvement may be a result of the direct effect of the dengue virus in susceptible individuals, or due to the effects of cytokine mediators and/or cellular components of the immune response.

Clinical features, electrocardiographic abnormalities, abnormal cardiac biomarkers, and echocardiographic findings have been evaluated in various studies as possible markers of cardiac involvement in dengue.

In our study, above findings also observed for cardiac involvement in dengue. 
The presence of electrocardiogram (ECG) abnormalities has been used by some authors to denote cardiac involvement in dengue.[11] A diverse range of ECG abnormalities have been reported with dengue, including rate and rhythm abnormalities, heart block, wave form abnormalities, and voltage abnormalities.[12-23]

Reported rhythm abnormalities include relative bradycardia,[13] sinoatrial block,[14] disorders of atrioventricular conduction (Junctional rhythm), ${ }^{[14,15]}$ seconddegree ${ }^{[16]}$ and complete heart block, ${ }^{[12,17]}$ and monomorphic premature ventricular contractions on a background of heart block,[16] atrial flutter,[18] transient ${ }^{[12,19]}$ and persistent ${ }^{[20]}$ atrial fibrillation, self-limiting tachy-brady arrhythmia,[24] sinoatrial block, and uniform ventricular ectopics progressing to ventricular bigeminy.[21] Electrocardiographic features mimicking acute myocardial infarction have also been reported.[23] ECG abnormalities may go undetected or asymptomatic.

Cardiac arrhythmias are other clinical manifestations of myocarditis. Various arrhythmias have been described during dengue virus infection such as atrial fibrillation, ventricular tachycardia and even atrioventricular blocks. These arrhythmias are associated to syncope and even sudden death. [25-27]

In our study, out of 104 dengue patients, abnormal ECG findings were in 28 patients (26.92\%), most common ECG finding was sinus bradycardia in 9 patients (32.14\%), next was sinus tachycardia in 7 patients $(25 \%)$, and $\mathrm{T}$ wave inversion in V1-V4 and V2-V5 was in 4 and 2 patients respectively. ST depression in V1-V4 and V1-V6 was in 3 patients each, generalised $\mathrm{T}$ inversion and low voltage in 3 patients each, ST-T changes in V2-V5 and V3-V6 both were in 2 patients each, generalised ST elevation and $\mathrm{T}$ wave inversion in lead 2, 3 were in 1 patient each.

Sinus bradycardia (Nimmannitiya S. et al) ${ }^{[26]}$ was the most conspicuous ECG finding with dengue fever but heart rate not useful.

Clinical manifestations suggesting cardiac involvement in dengue are diverse and include chest pain, palpitations, pleurisy, irregularities of pulse, bradycardia, hypotension, pulmonary oedema, and features of shock. ${ }^{[9,24]}$

It is known that tachycardia and hypotension is more frequently seen in DSS (Ranjit S et al).[27]

Also in our study 3 patients had hypotension and 7 patients had tachycardia, that is more common in DSS/DHF.

Thus, although this study provides some evidence that patients with ECG changes were more likely to develop hypotension and tachycardia or bradycardia, it does not provide convincing evidence that cardiac involvement was present.

In our study out of 104 dengue patients, we observed elevated CK-MB in 39 (37.50\%), troponin $\mathrm{T}$ test was positive in $9(8.65 \%)$ patients.

Myocardial involvement was subclinical as 2-D echo was normal in 17 patients (60.71\%). Possible cause of raised cardiac enzymes in these patients is subclinical myocarditis. Cardiac biomarkers may indicate the presence of cardiac involvement in dengue. A prospective study in Sri Lanka (Wichmann, et al) [28] evaluated several cardiac biomarkers (myoglobin, CK-MB, Troponin T, NT- pro-brain natriuretic peptide, heart-type fatty acid-binding protein), in patients with dengue $25 \%$ of patients had abnormal results in one or more biomarkers. However, the correlation between biomarkers and cardiac function has not been clearly demonstrated.

A study (Gupta V K et al) ${ }^{[29]}$ was conducted in New Delhi for estimating cardiac enzymes in 28 patients of Dengue fever. Estimation of cardiac enzymes was done in all patients. Significant level of CPK-MB was raised in 22 patients (78.55\%). Serum troponin T (Rapid card test) was weakly positive in 12 patients (42.8\%). Myocardial involvement was subclinical as 2-D echo was normal in 23 patients (82\%). Possible cause of raised cardiac enzymes in these patients was subclinical myocarditis.

Out of 104 dengue patients, the cardiac involvement was in 28 patients. Among these 28 patients, abnormal echo finding was present in 9 patients $(32.14 \%)$. The most common finding was mild pericardial effusion in 5 patients $(17.86 \%)$.

Echocardiographic evidence of myocardial involvement in dengue has been clearly demonstrated.[30,5,31,32,33]

In a study of 91 children with dengue, LVEF $<50 \%$ was observed in $6.7 \%, 13.8 \%$, and $36 \%$ of patients with DF, DHF, and DSS, respectively.

Similarly, in our study LVEF $<50 \%$ was observed in $3.57 \%$, $3.57 \%$ and $7.14 \%$ of patients with DF, DHF, and DSS, respectively.

In another study of 54 children under 12 years of age, LVEF was reduced $(<50 \%)$ in nine cases, and two had LVEF below 35\% (Kabra SK, et al) ${ }^{[10]}$

Satarasinghe et al[34] demonstrated echocardiographic evidence of myocarditis in $24 \%$ of patients with dengue, cardiac dilatation, the most commonly demonstrated echocardiographic evidence of myocarditis, more commonly affected - the right ventricle (57\%), and associated with tricuspid regurgitation. Left ventricular dilatation was seen in $21 \%$ of patients, and biventricular dilatation in $16 \%$.

In our study, we also observed that right ventricle dilation (7.14\%) was more common and it was associated with tricuspid regurgitation. Left ventricular dilatation was seen in $3.57 \%$ of patients.

Sengupta et al[30] also demonstrated similar evidence of myocarditis in patients with dengue, and suggest that twodimensional (2-D) speckle tracking echocardiography may be a more sensitive tool for the detection of early and subtle myocarditis.

Cardiac magnetic resonance (CMR) imaging, where available, may be of value in confirming the diagnosis of myocarditis, with a positive predictive value of $95 \%$ if at least two of the three diagnostic criteria are present.

\section{CONCLUSION}

A significant number of patients of dengue developed asymptomatic involvement of heart as evidenced by electrocardiography changes, raised cardiac enzymes (CPKMB, S. trop. T, LDH and SGOT). Myocardial involvement was subclinical as 2-D echo was normal in 17 patients (60.71\%).

Possible cause of raised cardiac enzymes in these patients is subclinical myocarditis. Asymptomatic myocarditis appears to be common in dengue, and spontaneous uneventful recovery is the norm. 
The presence of electrocardiographic abnormalities may suggest possible cardiac involvement.

Sinus bradycardia was the most conspicuous ECG finding; however, an echocardiogram is the gold standard for diagnosing myocardial involvement.

Further studies are needed to evaluate the haemodynamic impact of myocardial involvement in patients with severe dengue. Most forms of treatment currently are purely supportive, but with better understanding of the pathophysiology of dengue, targeted treatment may become possible.

\section{REFERENCES}

[1] Ross TM. Dengue virus. Clinical Lab Medics 2010;30:149-60.

[2] WHO dengue guidelines for diagnosis, treatment, prevention and control treatment, prevention and control treatment, prevention and control 2012.

[3] Dengue fever: overview-eMedicine infectious diseases Dengue/Dengue Fever eMedicine. medscape.com/article/215840-overview.

[4] Greaves K, Oxford JS, Price CP, et al. The prevalence of myocarditis and skeletal muscle injury during acute viral infection in adults: measurement of cardiac troponins I and T in 152 patients with acute influenza infection. Arch Intern Med 2003;163(2):165-8.

[5] Wali JP, Biswas A, Chandra S, et al. Cardiac involvement in dengue haemorrhagic fever. Int J Cardiol 1998;64(1):31-6.

[6] Kabra SK, Juneja R, Madhulika, et al. Myocardial dysfunction in children with dengue haemorrhagic fever. Natl Med J India 1998;11(2):59-61.

[7] Byung-Kwan Lim, Jae-Ok Shin, Seong-Choon Choe, et al. Myocardial injury occurs earlier than myocardial inflammation in acute experimental viral myocarditis. Experimental and Molecular Medicine 2005;37(1):517.

[8] Obeyesekere I, Hermon Y. Arbovirus heart disease: myocarditis and cardiomyopathy following dengue and Chikungunya fever-a follow-up study. Am Heart J 1973;85(2):186-94.

[9] Promphan W, Sopontammarak S, Pruekprasert P, et al. Dengue myocarditis. Southeast Asian J Trop Med Public Health 2004;35(3):611-3.

[10] Ehrhardt S, Mockenhaupt FP, Anemana SD, et al. High levels of circulating cardiac proteins indicate cardiac impairment in African children with severe plasmodium falciparum malaria. Microbes Infect 2005;7(11-12):1204-10.

[11] Kularatne SA, Pathirage MM, Kumarasiri PV, et al. Cardiac complications of a dengue fever outbreak in Sri Lanka, 2005. Trans R Soc Trop Med Hyg 2007;101(8):804-8.

[12] Saldarriaga C, Roncancio G, González N, et al. Manifestaciones cardiacas del dengue. Reporte de una serie de casos durante la epidemia colombiana de 2010. Rev Colomb Cardio 2013;20(6):366-9.

[13] Lateef A, Fisher DA, Tambyah PA. Dengue and relative bradycardia. Emerg Inf Dis 2007;13(4):650-1.
[14] Kaushik JS, Gupta P, Rajpal S, et al. Spontaneous resolution of sinoatrial exit block and atrioventricular dissociation in a child with dengue fever. Sing Med J 2010;51(9):e146-8.

[15] Donegani E, Briceno J. Disorders of atrioventricular conduction in patients with hemorrhagic dengue. Minerva Cardioangiolog 1986;34(7-8):477-80.

[16] Khongphatthallayothin A, Chotivitayatarakorn P, Somchit S, et al. Morbitz type I second degree AV block during recovery from dengue hemorrhagic fever. Southeast Asian J of Trop Med \& Pub Health 2000;31(4):642-5.

[17] Kohli U, Sahu J, Lodha R, et al. Invasive nosocomial aspergillosis associated with heart failure and complete heart block following recovery from dengue shock syndrome. Ped Crit Care Med 2007;8(4):389-91.

[18] Silva FT, da Silva GB, Benevides AN, et al. Atrial flutter complicating severe leptospirosis: a case report. Rev Soc Bras Med Trop 2013;46(2):246-8.

[19] HortaVeloso H, Ferreira JA, de Paiva BJM, et al. Acute atrial fibrillation during dengue hemorrhagic fever. Brazil J Inf Dis 2003;7(6):418-22.

[20] Mahmod M, Darul ND, Mokhtar I, et al. Atrial fibrillation as a complication of dengue hemorrhagic fever: non-self-limiting manifestation. Int J Inf Dis 2009;13(5):e316-8.

[21] Chuah SK. Transient ventricular arrhythmia as a cardiac manifestation in dengue haemorrhagic fever-a case report. Sing Med J 1987;28(6):569-72.

[22] La-Orkhun V, Supachokchaiwattana P, Lertsapcharoen $P$, et al. Spectrum of cardiac rhythm abnormalities and heart rate variability during the convalescent stage of dengue virus infection: a Holter study. An Trop Paed 2011;31(2):123-8.

[23] Lee $\mathrm{CH}$, Teo C, Low AF. Fulminant dengue myocarditis masquerading as acute myocardial infarction. Int J Cardiol 2009;136(3):e69-71.

[24] Lee IK, Lee WH, Liu JW, et al. Acute myocarditis in dengue hemorrhagic fever: a case report and review of cardiac complications in dengue-affected patients. Int J Inf Dis 2010;14(10):e919-22.

[25] Punja M, Mark DG, McCoy JV, et al. Electrocardiographic manifestations of cardiac infectious-inflammatory disorders. Am J Emerg Med 2010;28(3):364-77.

[26] Dengue NS. Dengue hemorrhagic fever. In: Manson's tropical diseases. 20 th edn. London: WB Saunders 1996:712-29.

[27] Ranjit S, Kissoon N, Gandhi D, et al. Early differentiation between dengue and septic shock by comparison of admission hemodynamic, clinical, and laboratory variables: a pilot study. Ped Emerg Care 2007;23(6):368-75.

[28] Wichmann D, Kularatne S, Ehrhardt S, et al. Cardiac involvement in dengue virus infections during the 2004/2005 dengue fever season in Sri Lanka. Southeast Asian J Trop Med Public Health 2009;40(4):727-30. 
[29] Gupta VK, Godpayle AK. Subclinical cardiac involvement in dengue hemorrhagic fever. JIACM 2010;11(2):107-11.

[30] Satarasinghe RL, Arultnithy K, Amerasena NL, et al. Asymptomatic myocardial involvement in acute dengue virus infection in a cohort of adult Sri Lankans admitted to a tertiary referral centre. Brit J Cardiol 2007;14:171-3.

[31] Khongphatthanayathin A, Lertsapcharoen P, Supachokchaiwattona $\mathrm{P}$, et al. Myocardial depression in dengue hemorrhagic fever: prevalence and clinical description. Pediatric Crit Care Med 2007;8(6):524-9.
[32] Khongphatthanayathin A, Suesaowalak M, Muangmingsook $S$, et al. Hemodynamic profiles of patients with dengue hemorrhagic fever during toxic stage: an echocardiographic study. Intensive Care Medicine 2003;29(4):570-4.

[33] Miranda CH, Mde BC, Matsuno AK, et al. Evaluation of cardiac involvement during dengue viral infection. Clin Inf Dis 2013;57(6):812-9.

[34] Sengupta SP, Nugurwar A, Jaju R, et al. Left ventricular myocardial performance in patients with dengue hemorrhagic fever and thrombocytopenia as assessed by two-dimensional speckle tracking echocardiography. Indian Heart J 2013;65(3):276-82. 